\title{
The effects of feedback valance and progress monitoring on goal striving
}

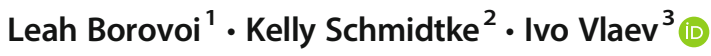 \\ Published online: 30 July 2020 \\ (C) The Author(s) 2020
}

\begin{abstract}
The current paper explores how people's goal strivings are influenced by feedback (positively valenced vs. negatively valenced), progress monitoring (remaining vs. accumulated) and goal specificity (vague vs. specific). Two laboratory-based experiments were performed. Experiment 1 reveals that, after receiving positively valenced feedback, participants who focus on accumulated progress show larger boosts in persistence than participants who focus on remaining progress. In contrast, after receiving negatively valenced feedback, participants who focus on remaining progress show larger boosts in persistence than participants who focus on accumulated progress. Experiment 2 extends the scope of the paper from understanding the effects of progress monitoring on goal striving to the effects goal specificity on goal striving. Experiment 2 shows that after receiving negatively valenced feedback, participants asked to consider specific goals (and so likely focus on remaining progress) show more persistence than participants asked to consider vague goals (and so likely focus on accumulated progress). These findings have important implications for motivation theory and applied practice.
\end{abstract}

Keywords Motivation · Goal striving $\cdot$ Feedback $\cdot$ Goals $\cdot$ Behavior change

Psychological theories of motivation largely fall within two categories: goal theories and attitude theories (Sloman 1996; Webb and Sheeran 2006). While motivation often unfolds in stages, with attitudes preceding goal formation, goal and attitude theories make conflicting predictions about the effects of feedback valence on goal striving. We propose that this conflict can be explained, at least in part, by an interaction between the type of feedback people receive and the type of progress monitoring they use.

The current paper has two sections. Section 1, including Experiment 1, examines the relationship between feedback

Ivo Vlaev

ivo.vlaev@wbs.ac.uk

Leah Borovoi

leah.borovoi@openu.ac.il

Kelly Schmidtke

kelly.a.schmidtke@warwick.ac.uk

1 Department of Psychology, Open University of Israel, Derekh ha-Universita 1, 4353701 Raanana, Israel

2 Warwick Medical School, University of Warwick, Coventry CV4 7AL, UK

3 Warwick Business School, University of Warwick, Scarman Road, Coventry CV4 7AL, UK valence and progress monitoring. Section 2, including Experiment 2, extends these findings to goal specificity. Specifically, each experiment measures goal striving according to an array of mechanisms posited by Locke and Latham (2002). In Experiment 1, goal striving is measured by assessing participants' performance (i.e. attention and effort) and persistence (i.e. time-spent) on a computer-based task. In Experiment 2, goal striving is measured via participants responses to a survey about their motivation to continue working towards specific and vague goals. The general discussion reviews limitations of this work and its implications for psychological theories of motivation and applied practice. The introduction of Section 1 first describes the effects of feedback valence and progress monitoring on goal striving.

\section{Section 1: Feedback Valence and Progress Monitoring}

\section{Feedback Valence}

The effects of positively and negatively valenced feedback on motivation have been examined using both goal and attitude theories. Many researchers focus on goal theories (e.g. Aarts and Dijksterhuis 2000; Berson et al. 2015; Kruglanski et al. 
2002; Gollwitzer and Moskowitz 1996; Locke and Latham 2002). Relevant to the present paper, Carver and Scheier's goal theory describes a feedback loop model (Carver and Scheier 1990; Carver and Scheier 1998; Carver and Scheier 2000). Within their model is a mental-monitor, called a metamonitor, which periodically compares an individual's current-state to their desired end-state. If a discrepancy is observed, the metamonitor signals the individual to reduce that discrepancy. When the rate of discrepancy reduction is too slow, the metamonitor signals the individual to speed up. When the rate of discrepancy reduction is too fast, the metamonitor signals the individual to slow down.

The feedback loop model is supported by observations that people's goal strivings tend to increase as the discrepancy between their current-state and desired end-state increases (Elliot and Church 1997; Gollwitzer 1999; Higgins 1987; Locke and Latham 2002; Miller et al. 1960; Pervin 1989). In so doing, goal theories make different predictions about the effects of positively and negatively valenced feedback on goal striving. Positively valenced feedback, saying that sufficient progress has been made, should decrease goal striving. In contrast negatively valenced feedback, saying that insufficient progress has been made, should increase goal striving.

Attitude theories also discuss the role of feedback on goal striving (Atkinson 1953; Fishbein and Ajzen 1974; Lewin et al. 1944; Tolman 1955). Attitude theories posit that psychological mechanisms, such as expectancy and self-efficacy, mediate the relationship between feedback and goal striving. For example, Wigfield and Eccles's (2000) expectancy value theory includes three components: ability beliefs, expectancies for success, and achievement values. 'Ability beliefs' describes whether one thinks they can perform a task. 'Expectancies for success' describes how well one believes they will perform a task. 'Achievement values' describes how valuable one perceives said achievements to be (Eccles 1983). When all three components are sufficiently high, goal striving tends to be stronger. As another example, Bandura's $(1986,1997)$ self-efficacy model suggests that positively valenced feedback increases persistence, while negatively valenced feedback decreases persistence (Locke and Latham 1990; Pintrich and Schunk 2002; Teunissen and Bok 2013). Note that the pattern predicted by attitude theories is the opposite of the pattern predicted by goal theories.

\section{Progress Monitoring}

Progress monitoring is a process by which one tracks their current-state from a start-state to an end-state. Such progress can be tracked as it pertains to 'remaining progress' or 'accumulated progress.' Remaining progress describes the distance between one's current-state and end-state. Louro et al.'s (2007) concept of goal proximity roughly aligns with our concept of remaining progress. Accumulated progress describes the distance between one's startstate and current-state or the rate at which one advances from their start-state to current-state. ${ }^{1}$

Goal theories and attitude theories focus on different types of progress monitoring. Largely, goal theories focus on remaining progress. Goal theories predict that people initially increase their efforts to reach a distant desired end-state and then reduce their efforts as they near the end-state. In contrast, largely, attitude theories focus on accumulated progress. Attitude theories predict that people will have trouble starting to reach a distant (or seemingly impossible) desired end-state and then increase their efforts as they near (or come to believe it is possible to attain) the desired end-state.

For example, suppose an author sets a goal to write 20 pages in a 5-day workweek by writing 4 pages each day. Further, assume that the author is keeping track of the number of pages they write each day and that by the end of day 2 the author has already written 15 pages. At this point, one may make different predictions about the author's goal striving if they appeal to goal or attitude theories. Appealing to goal theories, which focus on remaining progress, one will predict that the author will reduce their effort, because the author is closer to their goal than intended. In contrast, appealing to attitude theories, which focus on accumulated progress, one will predict that the author will increase their effort, because the author has an increased sense of self-efficacy.

\section{Present Study}

The present study investigates the interaction between the type of feedback people receive and the type of progress monitoring they use. Previous research by Fishbach et al. $(2005,2006)$ looked at this relationship in a naturally emerging context, as opposed to a randomized controlled trial. Their research distinguishes between self-regulation that is based on estimates of the distance to the end-state and self-regulation that is based on estimates of one's commitment to obtaining that endstate. Koo and Fishbach (2008) show that, when people's commitments are stronger, focusing on remaining progress tends to increase motivation; when people's commitments are weaker, focusing on accumulated progress tends to increase motivation. However, feedback valence was not explicitly manipulated in these studies, and so their research does not clearly describe how feedback valence and progress monitoring interact. The present study fills this gap by explicitly manipulating the type of feedback participants receive (positive

\footnotetext{
${ }^{1}$ Bonezzi et al. (2011) present a psychophysical model of this idea, using the terms 'progress to-go' and 'progress to-date' but do not test how such progress monitoring would interact with positive and negative feedback valance.
} 
vs. negative) and the type of progress monitoring they are primed to use (remaining vs. accumulated).

To determine how feedback valence interacts with progress monitoring, Experiment 1 was performed. In Experiment 1, participants searched for differences between pictures on a computer screen. Participants were primed to monitor their remaining progress or accumulated progress, and they received positively valenced feedback or negatively valenced feedback in the middle of the task. The results examine the change in participants' goal striving before and after that feedback. Two hypotheses are put forth to describe our anticipated results, each focused on a different hypothesis. ${ }^{2}$

Hypothesis 1: After receiving negatively valenced feedback, participants focusing on remaining progress will experience a larger boost in their performance and persistence than participants who focus on accumulated progress. If this hypothesis is correct, it would support goal theories of goal striving. Hypothesis 2: After receiving positively valenced feedback, participants who focus on accumulated progress will experience a larger boost in their performance and persistence than participants who focus on remaining progress. If this hypothesis is correct, it would support attitude theories of goal striving.

\section{Experiment 1}

In Experiment 1, participants were asked to search for differences between pairs of pictures. Using a $2 \mathrm{X} 2$ factorial design participants were primed to focus on different types of progress monitoring (remaining, accumulated) and received different types of feedback in the middle of the task (positive, negative). The four experimental conditions were as follows: Positively Valenced Feedback - Remaining Progress, Positively Valenced Feedback - Accumulated Progress, Negatively Valenced Feedback - Remaining Progress, and Negatively Valenced Feedback - Accumulated Progress. The dependent variables were the change in the number of differences participants found before and after receiving feedback (i.e. performance) and the change in the time they spent searching for the differences before and after receiving feedback (i.e. persistence).

\footnotetext{
2 The two hypotheses could be replaced with one interaction hypothesis: participants' goal striving will depend on the type of feedback they receive and the type of progress monitoring they use.
}

\section{Methods}

\section{Participants}

Fifty-four Tel Aviv University and Open University students $\left(M_{\text {age }}=24.5\right.$ years, $S D=4.3$, Female $\left.=41\right)$ participated in the study for course credit.

\section{Procedure}

Before the starting the task, half of the participants read a prime designed to focus their attention on remaining progress and the remaining half read a prime designed to focus their attention on accumulated progress. As primes that describe unnatural contexts may render it difficult for participants to respond, the primes describe naturally relevant but different contexts. The primes were each two paragraphs long and appear in Appendix 1. The accumulating progress prime involves a person tracking the distance they have already traveled to a job interview to determine if they could stop for coffee; an excerpt of this prime is provided here, "She left home an hour before the appointment time, but the bus got stuck in traffic and was barely crawling. Half an hour later, Ayala realized that she has passed less than a third of the way." The remaining progress prime involves a person estimating how much more fun they could have if they kept playing a game to determine if they want to keep playing; an excerpt of this prime is provided here, "She wants to enjoy the game and have more and more fun." The authors acknowledge that any effects found for the progress monitoring manipulations may therefore be due to the different contexts, but if the reader agrees that each context is more naturally disposed to trigger accumulated or remaining progress monitoring, this should only limit the generalizability of our findings.

After reading the progress monitoring prime, participants were asked to search for differences between 10 pairs of pictures on a computer screen, see Appendix 2. Upon completion of five pairs, participants received sham-feedback. Half of the participants received positively valenced sham-feedback: "You've completed half of the pictures, and found much more than half of the required differences. So far, you have 125 points." The other half received negatively valenced shamfeedback: "You've completed half of the pictures, and found much less than half of the required differences. So far, you have only 20 points."

Manipulation check items were presented to participants directly after they received the sham-feedback to assess whether they reacted to our feedback valence and progress monitoring primes as intended. The manipulation check items were not previously validated, rather their validity is limited to 'face-validity' (Nevo 1985). The manipulation checks asked participants to rate the extent to which 10 statements described them from 0 (not at all) to 7 (very much). The statements 
measuring a perceived focus on remaining progress included those also measuring perceived positive valence - "I have made much progress towards the goal," "The effort that I have made is worthwhile," and "I have concentrated and succeeded on the task from the start," - and perceived negative valence "I am not making progress towards the goal," and "I have been wasting my time since the start of the experiment". The statements measuring a perceived focus on accumulated progress also included those measuring perceived positive valence - "I'm close to attaining the goal," "I'm going to get the majority of points," and "I'm far from getting the majority of points," - and perceived negative valence - "I'll soon find almost all of the differences between pictures," and "I'm far away from attaining the goal."

The computer program recorded the number of differences participants found before and after receiving feedback (i.e. performance) and the time they spent searching for these differences before and after receiving feedback (i.e. persistence).

\section{Results and Discussion}

\section{Manipulation Checks}

Participants' responses to the manipulation checks are displayed in Table 1. Numbers displayed in bold text indicate alignment between participants' assigned conditions and their perceptions. Numbers displayed in un-bold text indicate misalignment. As expected, descriptively, the numbers indicating alignment are greater than those indicating misalignment.

\section{Feedback Valence Manipulation Check}

Participants largely reacted to their assigned feedback valence as intended. These data were analyzed using a mixedmeasures ANOVA with one between-subjects factor, Feedback-Valenced-Assigned (positive, negative), and one within-subjects factor, Feedback-Valence-Perceived (positive, negative). There was no main effect of Feedback-
Valenced-Assigned, $F(1,50)=0.35, p=0.56$. A significant main effect of Feedback-Valence-Perceived emerged, $F(1$, $50)=9.68, p<0.01, d=0.86$, indicating that participants reported more positive than negative thoughts.

As expected, a significant interaction emerged, $F(1,50)=$ $20.60, p<0.01, d=1.26$. After receiving positively valenced feedback, participants held more positive thoughts than negative thoughts $\left(M_{\text {positive }}=4.86, S D=0.86\right.$, vs. $M_{\text {negative }}=3.58, S D=$ 1.36). Additionally, after receiving negative feedback, participants held more negative thoughts than positive thoughts $(M$ positive $=2.51, S D=1.25$, vs. $M_{\text {negative }}=4.02, S D=0.88$ ).

\section{Progress Monitoring Manipulation Check}

Participants largely focused their attention on the type of progress monitoring intended. These data were analyzed using a repeatedmeasures ANOVA with one between-subjects factor, ProgressMonitoring-Assigned (remaining, accumulated), and one withinsubjects factor, Progress-Monitoring-Perceived (remaining, accumulated). There was a trending main effect of ProgressMonitoring-Assigned, $F(1,52)=4.13, p=0.05$. A significant main effect of Progress-Monitoring-Perceived did not emerge, $F(1,52)=1.36, p=0.25$.

A trending significant interaction emerged, $F(1,52)=3.70$, $p=0.06$. Participants who read the remaining progress prime reported more remaining than accumulated thoughts $(M$ remaining $=4.02, S D=0.83$ vs. $M_{\text {accumulated }}=3.87, S D=$ 0.76). Participants who read the accumulated progress prime reported more accumulated than remaining thoughts $(M$ remaining $=3.85, S D=1.46$ vs. $M_{\text {accumulated }}=3.27, S D=0.81$ ).

\section{Performance}

Change in participants' performance was defined as the difference between the number of differences participants located before and after receiving feedback. Pearson correlation between the number of items located before and after receiving feedback was strong, $r=0.66, p<0.01$. A between-
Table 1 Results of the manipulation checks (Standard Deviations in Parentheses)
Perceived

\begin{tabular}{|c|c|c|c|c|}
\hline & \multicolumn{2}{|c|}{ Remaining Progress } & \multicolumn{2}{|c|}{ Accumulated Progress } \\
\hline & Positive Valence & Negative Valence & Positive Valence & Negative Valence \\
\hline \multicolumn{5}{|c|}{ Assigned Remaining Progress } \\
\hline Positive feedback & $5.07(0.70)$ & $2.40(1.72)$ & $4.33(0.90)$ & $2.33(2.02)$ \\
\hline Negative feedback & $3.67(2.29)$ & $5.11(1.26)$ & $4.22(1.86)$ & $3.56(2.06)$ \\
\hline \multicolumn{5}{|l|}{ Accumulated Progress } \\
\hline Positive feedback & $4.73(1.58)$ & $2.67(0.90)$ & $5.33(0.90)$ & $2.67(1.35)$ \\
\hline Negative feedback & $3.80(1.65)$ & $4.53(1.12)$ & $2.93(0.96)$ & $3.13(0.74)$ \\
\hline
\end{tabular}


subjects ANOVA was run to test to test if each of the four groups preformed similarly before they received feedback, and they did not differ, $F(1,50)=1.04, p=0.31$.

The change data were analyzed using a between-subjects ANOVA with two factors, Progress-Monitoring (remaining vs. accumulated) and Feedback-Valence (positive, negative). There was no main effect of Progress-Monitoring, $F(1,50)=$ $0.93, p=0.34$. A significant main effect of Feedback-Valence emerged, $F(1,50)=5.64, p=0.02, d=0.66$, indicating that participants who received negatively valenced feedback increased their performance more than participants who received positively valenced feedback $\left(M_{\text {positive }}=2.62, S D=\right.$ 4.81 vs. $M_{\text {negative }}=6.02, S D=4.31$ ).

The interaction was significant, $F(1,50)=7.80, p<0.01$, $d=0.78$. This interaction aligns with both of our predictions. In the positively valenced feedback condition, participants who read the accumulated progress prime improved their performance more than participants who read the remaining progress prime $\left(M_{\text {remaining }}=0.67, S D=3.35\right.$ vs. $M_{\text {accumulated }}=$ $4.53, S D=6.36$ ). In the negatively valenced feedback condition, participants who read the remaining progress prime improved their performance more than participants who read the accumulated progress prime $\left(M_{\text {remaining }}=8.11, S D=2.14\right.$ vs. $M_{\text {accumulated }}=3.93, S D=6.38$; see Table 2). These results are displayed in Table 2.

\section{Persistence}

Change in participants' persistence was defined as the change in the time spent locating differences before and after receiving feedback. Pearson correlation between the time spent locating differences before and after receiving feedback was strong, $r=0.60, p<0.01$. A between-subjects ANOVA was run to test if each of the four groups preformed similarly before they received feedback. The results indicated no significant differences between groups, $F(1,50)=0.48, p=0.49$.

The change data were then analyzed using a betweensubjects ANOVA with two factors, Progress-Monitoring (remaining, accumulated) and Feedback-Valence (positive, negative). There was no main effect of Progress Monitoring, $F(1$, $50)=0.67, p=0.42$. A significant main effect of Feedback-
Valence emerged, $F(1,50)=6.87, p=0.02, d=0.72$, indicating that participants who received negatively valenced feedback increased the time they spent on the task more than participants who received positively valenced feedback $(M$ positive $=30.33, S D=90.88$ vs. $M_{\text {negative }}=71.33, S D=94.20$ ).

As expected, there was a significant interaction, $F(1,50)=$ $12.50, p<0.01, d=0.98$. This interaction aligns with both our predictions. After receiving positively valenced feedback, participants who read the accumulated progress prime increased the time they spent locating differences more than participants who read the remaining progress prime $\left(M_{\text {remaining }}=-14.00\right.$, $S D=34.08$ vs. $\left.M_{\text {accumulated }}=43.00, S D=56.06\right)$. After receiving the negatively valenced feedback, participants who read the remaining progress prime increased the time they spent locating differences more than participants who read the accumulated progress prime $(M$ remaining $=156.67, S D=$ 154.33 vs. $M_{\text {accumulated }}=17.67, S D=131.70$; see Table 2 ).

In summary, participants in Experiment 1 read different primes that influenced their progress monitoring focus and experienced different feedback valences. The results support both of our hypotheses. In support of hypothesis 1 (and goaltheories), after receiving negatively valenced feedback, participants who focus on remaining progress showed greater increases in their performance and persistence than participants who focus on accumulated progress. In support of hypothesis 2 (and attitude-theories), after receiving positively valenced feedback, participants who focus on accumulated progress showed greater increases in their performance and persistence than participants who focus on remaining progress.

\section{Section 2: The Effect of Goal Specificity and Feedback Valence on Motivation}

The first section of the paper examined the relationship between feedback valence and progress monitoring. Clearly, however, how progress is monitored is not always explicitly stated. Rather, the type of monitoring most readily available to a person trying to meet their goal may be implicitly derived from the way the goal is stated. Specifically, some goals are stated in a more or less abstract manner, e.g. to lose $10 \mathrm{~kg}$ vs.
Table 2 Change in Performance \& Persistence by Primed Progress Monitoring and Feedback Valence (Standard Deviations in Parentheses)

\begin{tabular}{llllll}
\hline \multicolumn{1}{l}{ Progress Monitoring } & & & \\
\hline Remaining & Performance* & Persistence (in seconds) & & Performance* & Persistence** (in seconds) \\
\hline Positive feedback & $0.67(3.35)$ & $-14.00(34.08)$ & & $4.53(6.36)$ & $43.02(56.06)$ \\
Negative feedback & $8.11(2.14)$ & $156.6(154.33)$ & & $3.93(6.38)$ & $17.67(131.70)$ \\
\hline *Performance was defined as the increase in the number of differences found after receiving feedback \\
**Persistence was defined as the increase in time spent on the task after receiving feedback
\end{tabular}


to be healthier, or to pass a university course vs. to learn that course's material. The second section of the paper examines the relationship between feedback valence and goal specificity. The relationship between progress monitoring and goal specificity are explained below.

\section{Goals Specificity}

Goals can be construed in more specific/concrete ways or vague/ abstract ways (Freitas et al. 2001; Locke and Lantham 1985). Goals can often be made more specific by making them quantitative (Locke and Lantham 1985). Chang et al. (2017) suggest that people find it easier to monitor their progress when their goal is put in a quantitative form, but say little about the interaction between the types of goals people set and feedback valence they receive while trying to achieve them.

The degree to which a goal is specific or vague likely affects which type of progress monitoring is most salient. Specific goals typically have more defined desired end-states, and this makes remaining progress more accessible. For example, image a person sets a specific goal to lose $1 \mathrm{~kg}$ a week to eventually lose $10 \mathrm{~kg}$ in 10 weeks. If the person loses $8 \mathrm{~kg}$ in 5 weeks, this positively valenced feedback should cause them to reduce their efforts. In contrast, if the person loses only $2 \mathrm{~kg}$ in 5 weeks, this negatively valenced feedback should cause them to increase their efforts.

Vague goals have less defined end-states, and this makes remaining progress difficult to calculate and so accumulated progress is more salient. For example, imagine that a person has a goal to be healthy, i.e. a vague goal with an undefined end-state. Further, imagine this person is told that they 'look very energetic today.' While such positive feedback provides information about the person's progress, they cannot use such information to calculate the remaining distance. However, the person may still experience enhanced self-efficacy and achievement expectancy, i.e. a sense of accumulated progress, and increase their efforts. Now, let us assume that the same person receives negative feedback, e.g. that they 'look ill today.' Such negatively valenced feedback may decrease their self-efficacy and achievement expectancy, decrease their sense of accumulated progress, and decrease their goal striving.

There has been no systematic investigation of the interaction between goal specificity and feedback valence on goal striving. The goal specificity mechanism predicts that when goals are specific people have greater access to their remaining progress than accumulated progress, and therefore will tend to focus on their remaining progress. In contrast, when goals are vague people have greater access to their accumulated progress than remaining progress, and therefore will tend to focus on their accumulated progress. The hypotheses put forth here are similar to the hypotheses put forward in the previous section. However, note that we expect the effects to be weaker here, because of the more indirect route through which goal specific primes might affect participants' progress monitoring.

Hypothesis 3: After receiving positively valenced feedback, participants who imagine a vague goal will show higher persistence than participants who imagine a specific goal.

Hypothesis 4: After receiving negatively valenced feedback, participants who imagine a specific goal will show higher persistence than participants who imagine a vague goal.

\section{Experiment 2}

In Experiment 2, participants were asked to imagine their motivation to pursue goals after receiving feedback. Using a $2 \mathrm{X} 2$ factorial design, we manipulated the goal specificity participants were asked to imagine (vague, specific) and the feedback valence they received (positive, negative). The participants read and responded to different scenarios. The four experimental conditions were as follows: Positively Valenced Feedback - Specific Goal, Negatively Valenced Feedback Specific Goal, Positively Valenced Feedback - Vague Goal, and Negatively Valenced Feedback - Vague Goal. The dependent variables were participants' responses to a survey about their motivations after reading each scenario.

\section{Methods}

\section{Participants}

Fifty-four students completed the study $\left(M_{\text {age }}=22.78\right.$ years, $S D=2.17$, Male $=8$ ).

\section{Procedure}

Participants were asked to imagine five different scenarios. The scenarios are briefly described here, with the specific goal version followed by the vague goal version in parentheticals: (1) increasing an exam score (study more), (2) losing weight (becoming more physically attractive), (3) feeling energetic without coffee (achieving physical health), (4) going out with three people on a regularly basis (improving social life), and (5) saving money (achieving financial independence). The full scenarios, translated from Hebrew to English, are provided in Appendix 3. For the academic goal, the relevant scenarios are given below:

- Specific - Negative: Despite failing the midterm, your goal is to have a good average, so you want a $90 \%$ in the final. 
- Vague - Negative: Despite failing the midterm, you set a goal to study a lot, so that you will improve and understand the material.

- Specific - Positive: You succeeded in the midterm. Your goal is to get a good average, so you want to get a $90 \%$ in the final.

- Vague - Positive: You succeeded in the midterm. You set a goal to study a lot, so that you will improve and understand the material.

After specifying each goal, participants received feedback. Participants who received the Specific - Negative or Vague - Negative scenarios received negatively valenced feedback. Participants who received the Specific - Positive or Vague - Positive scenarios received positively valenced feedback.

- Negatively valenced feedback: Suppose that you failed in the mid-semester exam.

- Positively valenced feedback: Suppose that you succeeded in the mid-semester exam.

After reading and receiving feedback about each scenario, participants then rated how motivated they would be to achieve the goal after the mid-semester exam. To do this they answered six questions about persistence using a Likert scale from 0 (indicates very low persistence) to 7 (indicates higher persistence). The questions asked participants: (1) If they would continue to invest in the goal more or less than before?; (2) If they would you give up or invest more in the goal?; (3) If they would want to achieve the goal more or less than before?; (4) If they would think and invest in other means to achieve the same goal more or less than before?; (5) Whether the chance that they would give up was more or less than before?; and (6) Whether the chance that they would decide to invest their efforts in something else is higher or lower than before? These items were summed into the index called 'persistence' (relevant items were reverse scored). Manipulation checks were not included in Experiment 2 to limit the amount of time required to participate in the study. This limitation is more fully explored in the discussion.

\section{Results and Discussion}

To test the effect of goal specificity and feedback valence on persistence, participants' reported persistence was analyzed using a mixed-measures ANOVA with two betweensubjects factors and one within-subjects factor. The betweensubjects factors included Goal- Specificity (specific, vague) and Feedback-Valence (positive, negative). The withinsubjects factor included the Scenario (academic, weight, health, socializing, finance).
A significant main effect of Goal-Specificity emerged, $F(1$, 58) $=6.72, p=0.01, d=0.67$, indicating that participants in the specific goal condition tended to report higher persistence than participants in the vague goal condition (see Table 3 ). A significant main effect of Feedback-Valence emerged, $F(1$, 58) $=13.95, p<0.001, d=0.96$, indicating that participants in the negatively valenced feedback condition reported higher persistence than participants in the positively valenced feedback condition. A significant main effect of scenario emerged, $F(1,58)=16.48, p<0.01, d=1.04$, indicating that reported persistence was scenario-dependent.

Next the two-way interactions were examined. There was no interaction between Goal-Specificity and Scenario, $F(1,58)=$ $0.53, p=0.47$. A significant interaction between FeedbackValence and Scenario emerged, $F(1,58)=7.55, p<0.01$, $d=0.71$, indicating that in some scenarios positively valenced feedback produced higher persistence, whereas in other scenarios negatively valenced feedback produced higher persistence. Table 3 shows the mean results by scenarios to help understand the interaction. Specifically, for the weight scenario motivation was higher after positive feedback, while for all other scenarios motivation was higher after negative feedback.

As predicted, a significant two-way interaction between Goal-Specificity and Feedback-Valence emerged, $F(1,58)=5.82, p=0.02, d=0.63$. This interaction supports our predictions about positively valenced feedback and our predications about negatively valenced feedback. After receiving positively valenced feedback, participants' reported persistence was higher for the vague goal condition $(M=3.54, S D=0.63)$ than the specific goal condition $(M=3.46, S D=1.01)$. After receiving negatively valenced feedback, participants' reported persistence was higher for the specific goal condition $(M=$ 4.53, $S D=0.97)$ than the vague goal condition $(M=$ $3.69, S D=0.77)$. The three-way interaction was not significant, $F(3,58)=0.91, p=0.34$, indicating that the interaction between goal and feedback was not dependent on the scenario. In summary, Experiment 2 explored the effect of goal specificity and feedback valence on persistence. The results support both hypothesis 3 and, to a larger extent, hypothesis 4.

\section{General Discussion}

The experiments reported here reveal a potential new mechanism underpinning the impact of feedback, progress monitoring and goal specificity on people's goal striving. Experiment 1 suggest that progress monitoring (remaining vs. accumulated) affects whether feedback valence (positive vs. negative) decreases or increases goal striving. Experiment 2 find a similar relationship, here between negatively valenced feedback and specific 
Table 3 Reported Persistence by Goal Specificity and Feedback Valence (Standard Deviations in Parentheses)

\begin{tabular}{llll}
\hline Scenario & Specific goal & Vague goal & $\begin{array}{l}\text { Scenario Marginal } \\
\text { Means }\end{array}$ \\
\hline Academic & Get $90 \%$ & Study & \\
Positive feedback & $4.50(0.88)$ & $4.61(0.98)$ & $4.56(0.94)$ \\
Negative feedback & $5.02(1.07)$ & $4.16(1.03)$ & $4.59(1.36)$ \\
Weight Loss & Lose $5 \mathrm{~kg}$ & Improve appearance & \\
Positive feedback & $4.15(0.81)$ & $3.48(0.56)$ & $3.82(0.97)$ \\
Negative feedback & $3.71(0.67)$ & $3.42(0.70)$ & $3.57(0.74)$ \\
Social & Go out with 3 people & Improve social life & $3.00(1.60)^{*}$ \\
Positive feedback & $2.67(1.37)$ & $3.33(1.54)$ & $4.65(1.86)$ \\
Negative feedback & $5.20(1.26)$ & $4.09(1.70)$ & $3.61(1.21)^{*}$ \\
Financial & Save money & Financial independence & $4.87(1.95)$ \\
Positive feedback & $3.83(1.26)$ & $3.38(0.96)$ & $2.56(1.38)$ \\
Negative feedback & $5.43(1.43)$ & $4.31(1.74)$ & $2.86(1.67)$ \\
Health & Energy without coffee & Physical health & \\
Positive feedback & $2.13(1.25)$ & $2.92(0.99)$ & \\
Negative feedback & $3.27(1.79)$ & $2.45(1.03)$ & \\
Overall & Specific goal & Vague goal & \\
Positive feedback & $3.46(1.01)$ & $3.54(0.63)$ & $3.69(0.77)$ \\
Negative feedback & $4.53(0.97)$ & $3.62(0.67)$ & \\
Total & $3.99(1.09)$ & & \\
\hline
\end{tabular}

*Significant difference between positive and negative feedback at a 0.001 level goals (thought to highlight remaining progress), and between positively valenced feedback and vague goals (thought to highlight accumulated progress).

The results suggest the importance of progress monitoring and goal specificity in determining behavioral reactions to feedback. The results of the present studies are consistent with other work that has shown the importance of the goal specificity and feedback (Aarts and Dijksterhuis 2000; Belding et al. 2015; Fishbach and Dhar 2005; Fishbach et al. 2006; Förster et al. 2005; Gollwitzer and Moskowitz 1996; Hsee and Abelson 1991; Karsh and Eyal 2015; Kluger and DeNisi 1996; Locke and Latham 2002). The present experiments focused on unexplored aspects of goals striving and discovered that progress monitoring and goal specificity are indeed important factors that determine how feedback valence affects goal striving.

Our results for remaining progress largely align with the findings of Louro et al.'s (2007) findings for goal proximity. When goal attainment is near (i.e. remaining progress is small), positive emotions (positive feedback) decrease effort and negative emotions (negative feedback) increase effort. However, Louro et al.'s experiments do not manipulate something akin to accumulated progress. It is outside the scope of the present article to comment further than to say that it would be interesting direction for future research to explore the interaction between progress monitoring focus (remaining vs. accumulated) and goal proximity (far or near).

\section{Limitations of our Research / Opportunities for Future Research}

A limitation of both experiments is that sample-size was not calculated before participants were recruited. Planning for a sufficient sample-size mitigates the chance of type 1 and 2 errors, and future studies should do so (Banerjee et al. 2009). Another limitation is that Experiment 2 did not include manipulation checks. Two types of manipulation checks would have been useful. The first would have checked whether participants maintain the initially primed goal specificity. This is important because goals can change overtime, as discussed further in the 'connections to past research' section. The second would have checked that participants focused on remaining progress when given specific goals and accumulated progress when given vague goals. This is important as there are plausibly other mechanisms by which goal specificity interacts with feedback valence to affect goal striving.

Our work does not address several issues raised by other researchers in their approaches. For example, whether a goal is framed as approach (i.e. no negative end-state) or avoidance (i.e. no positive end-state) is 
both emotionally and behaviorally consequential (Avnet and Higgins 2006; Förster et al. 1998; Freitas and Higgins 2002; Higgins 2000; Higgins et al. 2003; Idson et al. 2004; Shah et al. 1998). These additional mechanisms highlight opportunities for future research. Future research might also explore the possibility that individual differences are moderating the effects we find. Such individual differences may include mastery, personal agency, and tolerance towards uncertainty. A separate direction future research might take pertains to the external validity of our findings. Notably, our experiments were performed in a laboratory setting.

\section{Connections to Past Research}

Our results have important implications for some theories of self-regulation (Carver and Scheier 1998; Elliot and Church 1997; Gollwitzer 1999; Locke and Latham 2002; Pervin 1989). Often such theories state that selfregulation is directed towards reducing the discrepancy between the current-state and the goal-state (i.e. remaining progress). We find that goal specificity and progress monitoring moderate this effect. Specifically, people assess feedback in terms of remaining progress more when they pursue specific goals with clear end-points.

Readers may note connections between our findings and other literatures. Notably, our distinction between vague and specific goals is reminiscent of Vallacher and Wegner's (1989) levels of action identification. Action Identification Theory describes how the same action can be identified at lower- or higher-levels. Lower levels of identification stress 'how' the behavior is preformed while higher levels stress 'why' the behavior is performed. For example, 'driving a car quickly' is a lower-level of identification undertaken to achieve some higher-level of identification, e.g. 'getting to work on time.' While people can entertain only one identification at a time (Vallacher and Wegner 1989; Vallacher, Wegner, and Somoza 1989), they can change identifications across time and circumstances. For example, people tend to replace easy lower-level identifications with higher-level identifications to assign greater purpose or meaning to their actions. Conversely, when people encounter challenging circumstances (say 'driving to work on an icy road') they may embrace lower levels of identifications to alleviate harmful stressors. It is difficult to say whether our participants maintained their assigned goal type through their session. Future experiments should include manipulation checks to ascertain whether participants retained the type of goal the experimenter intended.

Our distinction between specific and vague goals likely also bears on work regarding the distinction between concrete and abstract concepts. Both distinctions are relative rather than absolute. According to Construal Level Theory, goals that are psychologically more distant tend to be represented more abstractly and goals that are psychologically nearer tend to be represented more concretely. Research suggests that vague goals increase persistence more than abstract goals (Fujita et al. 2006). However, holding psychological distance constant, no research has directly investigated how positively or negatively valenced feedback affects people's goal striving. One may posit that goal abstractness and goal specificity relate to the same underlying concepts; however, this is an open question for future research to address.

\section{Implications for Applied Work}

The present findings also have implications for applied work, e.g. clinicians, educators, and organizations attempting to persuade people to adhere to their own academic, health-related, financial and social goals (Berson et al. 2015; Higuchi et al. 2010; Higuchi and Harashima 2012). Regarding academic goals, a related line of research has already looked whether students given self-transcendent goals to pursue academic work (i.e. abstract, higher-level motives) tend to be more motivated to pursue that work. For example, Yeager et al. (2014) found that participants who read about selftranscendent reasons for completing boring math problems tended to complete more math problems than participants who did not. Similarly, Davis et al. (2016) found that students who construed their academic goals at on a higher level (i.e. more abstract) had higher selfreported motivation to achieve them. Neither of these studies considered how giving participants positively or negatively valence of feedback on their progress might interact with their abstract or concrete goals.

Regarding therapists, possibly people who adopt vague goals may be prone to focus on negatively valenced aspects of their progress that further depletes their motivation and may increase their depression (Beck et al. 1987). Strategies already employed by therapists are designed to help people break out of these negative spirals by promoting their self-efficacy with positive feedback, which according to our findings may enhance motivation towards vague goals. Many therapists also help clients set more specific goals, where according to our findings a tendency to focus on negative feedback may prove more beneficial.

Regarding increasing the motivational strength in pursuit of personal goals, people can motivate themselves by reframing their goals as either vague or specific depending on the valence of the feedback they receive. For example, students who set vague goals (e.g. to 
learn) can be motivated by focusing on positively valenced feedback, whereas students who set specific goal (e.g. to get $90 \%$ on a test) can be motivated by focusing on negatively valenced feedback. Regarding persuasion, policy makers and social agents can persuade people by adopting different communicational strategies (Joshi and Wakslak 2014; Karsh and Eyal 2015). Such strategies should consider how people frame their goals, as this information influences whether positively or negatively valenced feedback supports their goal striving.

\section{Conclusions}

The present research highlights the importance of progress monitoring, goal specificity and feedback-valence on people's motivations for goal striving. Progress monitoring may come in two forms, remaining progress and accumulated progress. While specific goals likely invite one to monitor their remaining progress, vague goals invite one to monitor their accumulating progress. The feedback valence one receives interacts with the types of progress monitoring they use to affect their goal-related persistence. There are also benefits of negatively valenced feedback for people focused on remaining progress monitoring as well as benefits of positively valenced feedback for people focused on accumulated progress monitoring.

Acknowledgments We thank Nira Liberman for extremely helpful comments and suggestions.

\section{Compliance with Ethical Standards}

Conflict of Interest All authors declares that they have no conflict of interest.

Ethical Approval All procedures performed in studies involving human participants were in accordance with the ethical standards of the institutional and/or national research committee and with the 1964 Helsinki declaration and its later amendments or comparable ethical standards.

Informed Consent Informed consent was obtained from all individual participants included in the study.

\section{Appendix 1: Experiment 1 - Primes}

\section{Accumulated Progress Prime}

Ayala was going to a job interview from Netanya to Tel Aviv. Her aim was simple, to get to a job interview on time. Ayala knew that driving time ranges from $20 \mathrm{~min}$ to $90 \mathrm{~min}$, depending on traffic. She left home an hour before the appointment time, but the bus got stuck in traffic and was barely crawling. Half an hour later, Ayala realized that she has passed less than a third of the way. Ayala felt tense, anxious and very worried. She took her cell phone to call and tell about the expected delay, but since she could not even estimate when the bus would arrive, she put the phone back into her bag in despair. Ayala became more and more nervous, irritated, annoyed and confused since there would be chance to make a first impression. The passengers around Ayala also were very angry and annoyed too because of the unexpectedly delayed and canceled plans.

A week later, Ayala went to another job interview. Again, she traveled from Netanya to Tel Aviv. The interview took place at a different time. She left the house an hour before the time of an appointment, but the bus came soon, there were no traffic jams, no replacements and no unnecessary delays. Ayala saw that merely within $15 \mathrm{~min}$, she passed more than two-thirds of the way. She realized that she would reach the target place in $25 \mathrm{~min}$, so she could spend the spare time pleasurably in the nearest coffee shop. She sat comfortably in the café, and drank her coffee with a delicious croissant. Everything was peaceful and calm. Ayala came to the interview fresh and satisfied feeling that life also brings pleasant surprises from time to time.

\section{Remaining Progress Prime}

Ayala goes out with her friends for a bowling game for the first time. She chooses the right ball and uses a trial and error method to learn how to send the ball straight to the pins. She tries, but soon she sees that she is not moving anywhere. Her friends try to help her enjoy the game, but are not successful. As time passes, Ayala feels more and more frustration and despair. She is angry at the machine that produces unsuitable balls and the weak lighting that interferes with her ability to throw the balls effectively. She feels victimized by the selfishness of those friends who invited her to the boring game. By the end she feels sad and leaves early.

A week later Ayala goes out with her friends to try go-karting for the first time. She gets on the track and nothing can stop her. The level of adrenaline rises. She makes laps around the track, effectively overcomes faults and takes risks to win. Ayala reveals that her driving skills and her sense of coordination are improving tremendously. She is proud of her accomplishments, feels enthusiastic and full of energy. She wants to enjoy the game and have more and more fun. 


\section{Appendix 2: Experiment 1 - Pictures}
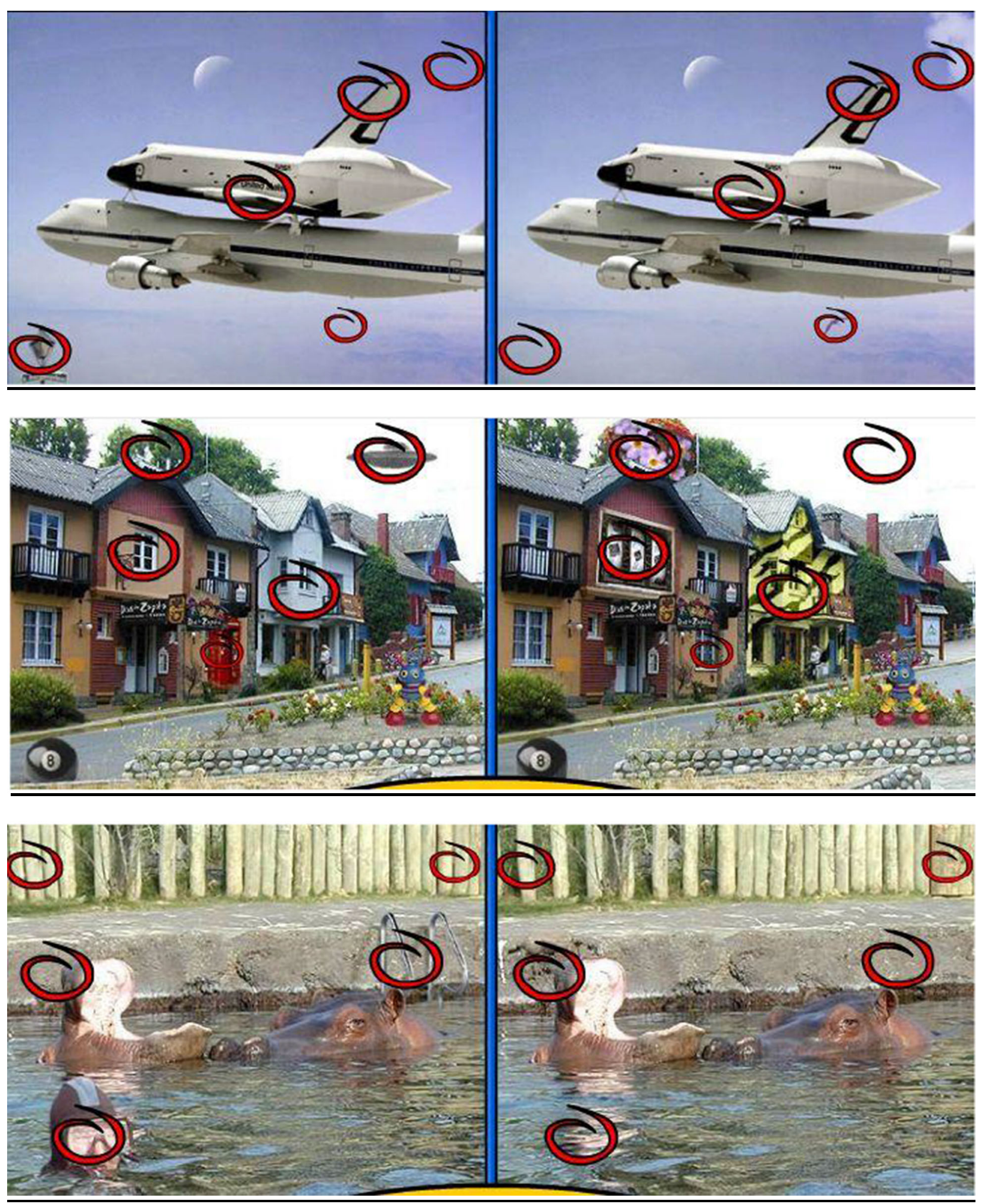

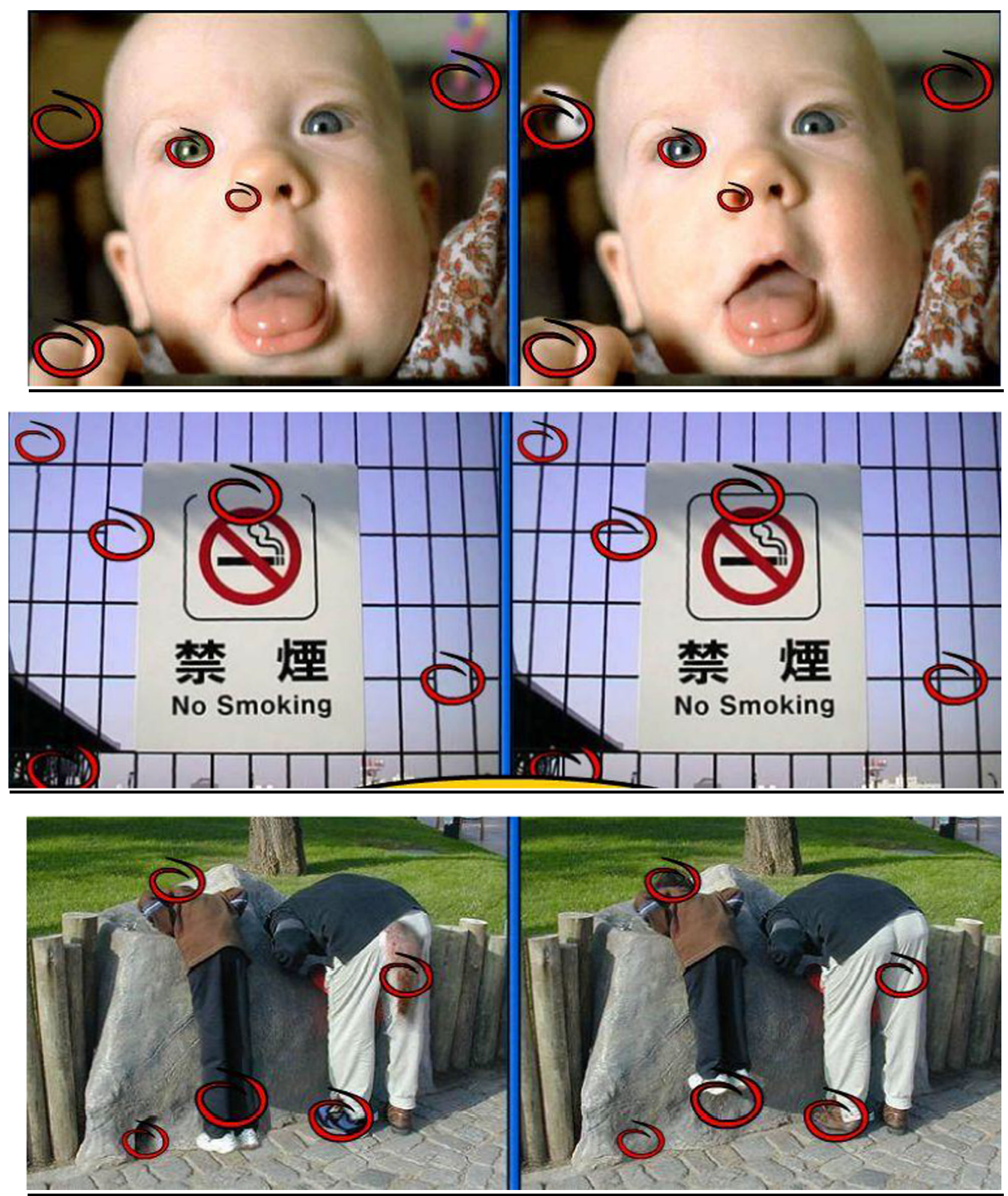

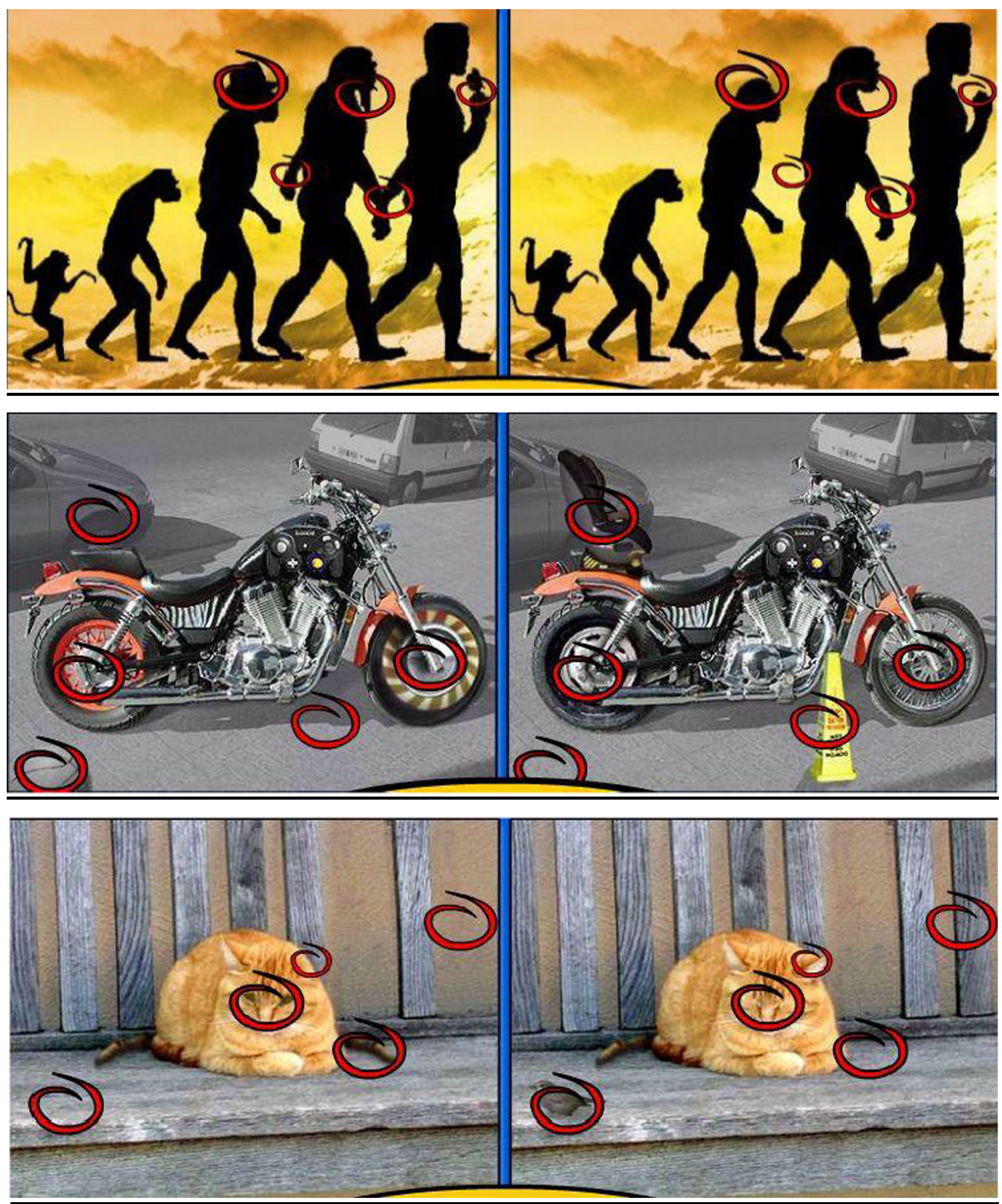

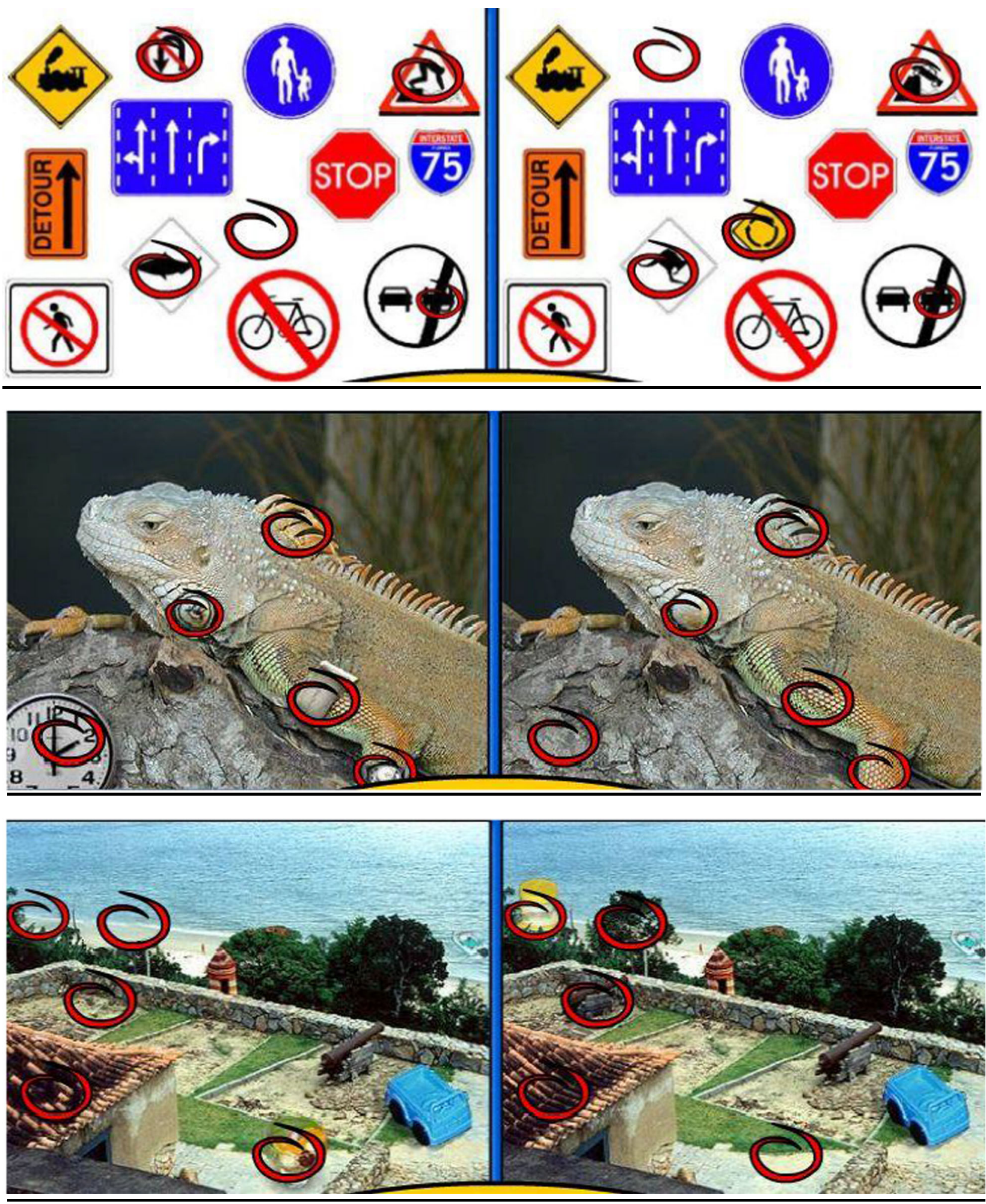

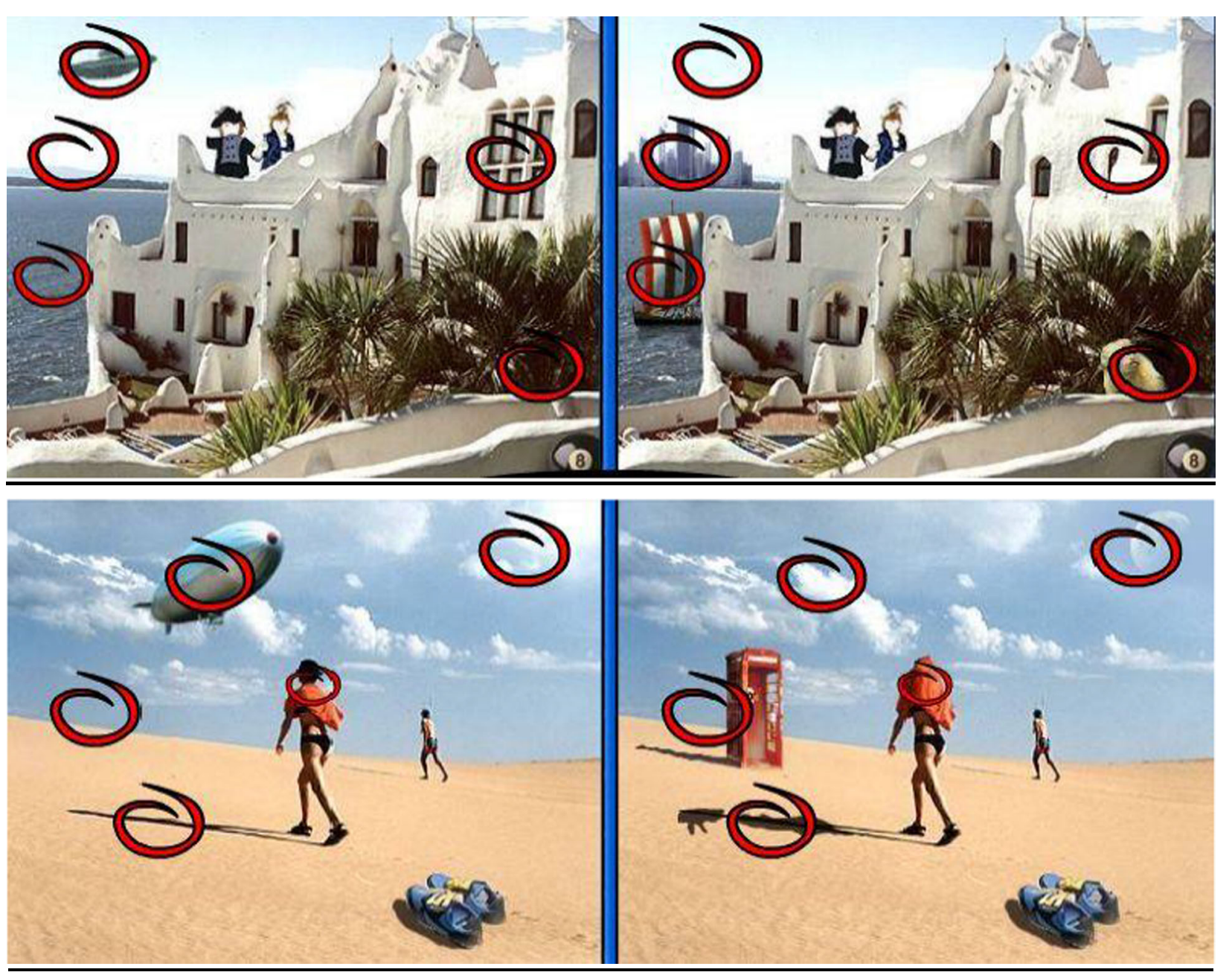


\section{Appendix 3: Experiment 2 - Scenarios}

\section{Table 4}

\begin{tabular}{|c|c|c|c|}
\hline Scenario & Feedback & Version & Scenario \\
\hline \multirow[t]{5}{*}{ Academic } & & & $\begin{array}{l}\text { You feel that it's not going well in one of the courses, but it's an important course for you to succeed. You do not } \\
\text { understand large parts of the material. You decided to invest more in studies, repeat previous material, make } \\
\text { summaries, and practice more during the course of your studies. }\end{array}$ \\
\hline & Negative & Specific & Despite failing the midterm, your goal is to have a good average so you want a $90 \%$ in the final. \\
\hline & & Vague & Despite failing the midterm, you set a goal to study a lot, so that you will improve and understand the material. \\
\hline & Positive & Specific & You succeeded in the midterm. Your goal is to get a good average so you want to get a $90 \%$ in the final. \\
\hline & & Vague & You succeeded in the midterm. You set a goal to study a lot, so that you will improve and understand the material. \\
\hline $\begin{array}{c}\text { Weight } \\
\text { loss }\end{array}$ & & & $\begin{array}{l}\text { One day you look in the mirror and feel disappointed with how you look. You feel like you're weighing too much. You } \\
\text { decide to change your life routine and maintain weight. You decide to eat healthier food and exercise. Your goal is } \\
\text { clear: get down five pounds in two months. }\end{array}$ \\
\hline
\end{tabular}

Negative Specific Your goal is clear: lose (or gain) $5 \mathrm{~kg}$ in 2 months. You're doing what you chose, but after a while the scale tells you you're not progressing.

Vague Your goal is to feel better with your body. You're doing what you chose to do, and after a month the scale tells you you're not progressing.

Positive Specific Your goal is clear: lose $5 \mathrm{~kg}$ in 2 months. You're doing what you decided to do and after a month the scales tells you you're progressing well.

Vague Your goal is to feel better with your body. You're doing what you decided to do and after a month the scale tells you you're doing well.

Health

In the past few weeks, you have been feel

ing tired, it's hard for you to concentrate on what you're doing and you just drop into bed at the end of the day. You decide to start exercising, go to yoga, or go for a walk several times a week.

Negative Specific Your goal is to work out until you can go up the stairs (walk or run) twice as much as you can now without getting tired. You're doing what you chose, but everyone tells you you're not fit.

Vague Your goal is to feel healthy naturally. You're doing what you decided to do for a month and one day you notice you needed 3 cups of coffee to stay awake during class.

Positive Specific Your goal is to feel alert during classes without coffee. You're doing what you decided to do for a month and one day you notice you hadn't drank coffee I two days and you feel fresh.

Vague Your goal is to be healthy and feel well naturally. You're doing what you decided to do for a month and one day you notice you hadn't drank coffee in two days and you feel fresh.

Social

You're in a new place (university, for example) and you don't know anyone. You have no friends you can just call or go out with. You decide to go to new places where you can meet new people, or meet friends through friends. You sit in class next to people and try to strike a conversation.

Negative Specific Your goal is to find a group of friends (3 people for example) you can consistently go out with. But despite your efforts people still don't call you and don't try to set up activities after school. You have no one to talk to between classes.

Vague Your goal is to have good and close friends. But despite your efforts people still don't call you and don't try to set up activities after school. You have no one to talk to between classes.

Positive Specific Your goal is to find a group of friends (3 people, for example) you can consistently go out with. After a while people want to sit next to you and call you trying to see you after class.

Vague Your goal is to have good and close friends. After a while people want to sit next to you, call you and try to see you after class.

Financial

You're not financially independent and you're tired of asking for money from your parents. You're spending a lot of money for living, class and going out, but you can't afford things you want and need. You decide to find a job that doesn't clash with your classes or (if you already have a job) double your work hours and save some cash.

Negative Specific Your goal is to stop asking your parents for money. You're doing what you decided to do, but your bank account is still in the negative.

Vague Your goal is to reach financial comfort. You're doing what you decided to do, but your bank account is still in the negative

Specific Your goal is to save 500 [monetary units]. You're doing what you decided to do and your bank account shows signs of recovery.

Vague Your goal is to reach financial comfort. You're doing what you decided to do and your bank account is showing signs of recovery. 
Open Access This article is licensed under a Creative Commons Attribution 4.0 International License, which permits use, sharing, adaptation, distribution and reproduction in any medium or format, as long as you give appropriate credit to the original author(s) and the source, provide a link to the Creative Commons licence, and indicate if changes were made. The images or other third party material in this article are included in the article's Creative Commons licence, unless indicated otherwise in a credit line to the material. If material is not included in the article's Creative Commons licence and your intended use is not permitted by statutory regulation or exceeds the permitted use, you will need to obtain permission directly from the copyright holder. To view a copy of this licence, visit http://creativecommons.org/licenses/by/4.0/.

\section{References}

Aarts, H., \& Dijksterhuis, A. (2000). Habits as knowledge structures: Automaticity in goal-directed behavior. Journal of Personality and Social Psychology, 78(1), 53-63.

Avnet, T., \& Higgins, E. T. (2006). How regulatory fit impacts value in consumer choices and opinions. Journal of Marketing Research, 43(1), 24-27.

Atkinson, J. W. (1953). The achievement motivation and recall of interrupted and completed tasks. Journal of Experimental Psychology, 46(6), 381-390.

Bandura, A. (1986). Social foundations of thought and action: A social cognitive. Englewood Cliffs, New Jersy: Prentice Hall.

Bandura, A. (1997). Self-efficacy: The exercise of control. New York: Freeman.

Banerjee, A., Chitnis, U. B., Jadhav, S. L., Bhawalkar, J. S., \& Chaudhury, S. (2009). Hypothesis testing, type I and type II errors. Industrial Psychiatry Journal, 18(2), 127-131.

Beck, A. T., Rush, A. J., Shaw, B. F., \& Emery, G. (1987). Cognitive therapy of depression. New York: Guilford Press.

Belding, J. N., Naufel, K. Z., \& Fujita, K. (2015). Using high-level construal and perceptions of changeability to promote self-change over self-protection motives in response to negative feedback. Personality and Social Psychology Bulletin, 41(6), 822-838.

Berson, Y., Halevy, N., Shamir, B., \& Erez, M. (2015). Leading from different psychological distances: A construal-level perspective on vision communication, goal setting, and follower motivation. Leadership Quarterly, 26(2), 143-155.

Bonezzi, A. C., Brendl, M., \& De Angelis, M. (2011). Stuck in the middle: The psychophysics of goal pursuit. Psychological Science, 22(5), 607-612.

Carver, C. S., \& Scheier, M. F. (1990). Origins and functions of positive and negative affect: A control-process view. Psychological Review, 97(1), 19-35.

Carver, C. S., \& Scheier, M. F. (1998). On the self-regulation of behavior. New York: Cambridge University Press.

Carver, C. S. \& Scheier, M. F. (2000). Perspectives on personality (4th ed.) Boston: Allyn and Bacon.

Chang, B. P. I., Webb, T. L., Benn, Y., \& Stride, C. B. (2017). Which factors are. associated with monitoring goal progress? Frontiers in Psychology, 8, 434.

Davis, W. E., Kelley, N. J., Kim, J., Tang, D., \& Hicks, J. A. (2016). Motivating the academic mind: High-level construal of academic goals enhances goal meaningfulness, motivation, and self-concordance. Motivation and Emotion, 40, 193-202.

Eccles, J. (1983). Expectancies, values, and academic behaviors. In J. T. Spence (Ed.), Achievement and achievement motives: Psychological and sociological approaches (pp. 75-146). San Francisco, CA: W. H. Freeman.
Elliot, A. J., \& Church, M. A. (1997). A hierarchical model of approach and avoidance achievement motivation. Journal of Personality and Social Psychology, 72(1), 218-232.

Fishbach, A., \& Dhar, R. (2005). Goals as excuses or guides: The liberating effect of perceived goal progress on choice. Journal of Consumer Research, 32(3), 370-377.

Fishbach, A., Dhar, R., \& Zhang, Y. (2006). Subgoals as substitutes or complements: The role of goal accessibility. Journal of Personality and Social Psychology, 91(2), 232-242.

Fishbein, M., \& Ajzen, I. (1974). Attitudes toward objects as predictors of single and multiple behavior criteria. Psychological Review, 81(1), $59-74$.

Förster, J., Higgins, E. T., \& Idson, L. C. (1998). Approach and avoidance strength during goal attainment: Regulatory focus and the "goal looms larger" effect. Journal of Personality and Social Psychology, 75(5), 1115-1131.

Förster, J., Liberman, N., \& Higgins, E. T. (2005). Accessibility from active and fulfilled goals. Journal of Experimental Social Psychology, 41(3), 220-239.

Freitas, A. L., Salovey, P., \& Liberman, N. (2001). Abstract and concrete self-evaluative goals. Journal of Personality and Social Psychology, $80(3), 410-412$.

Freitas, A. L., \& Higgins, E. T. (2002). Enjoying goal-directed action: The role of regulatory fit. Psychological Science, 13(1), 1-6.

Fujita, K., Trope, Y., Liberman, N., \& Levin-Sagi, M. (2006). Construal levels and self-. control. Journal of Personality and Social Psychology, 90(3), 351-367.

Gollwitzer, P. M. (1999). Implementation intentions: Strong effects of simple plans. American Psychologist, 54(7), 493-503.

Gollwitzer, P. M., \& Moskowitz, G. B. (1996). Goal effects on action and cognition. In E. T. Higgins \& A. W. Kruglanski (Eds.), Social psychology: Handbook of basic principles (pp. 361-399). New York: Guilford Press.

Higgins, E. T. (1987). Self-discrepancy: A theory relating self and affect. Psychological Review, 94(3), 319-340.

Higgins, E. T. (2000). Making a good decision: Value from fit. American Psychologist, 55(11), 1217-1230.

Higgins, E. T., Idson, L. C., Freitas, A. L., Spiegel, S., \& Molden, D. C. (2003). Transfer of value from fit. Journal of Personality and Social Psychology, 84(6), 1140-1153.

Higuchi, O., \& Harashima, M. (2012). The influence of construal level and achievement goal on prediction. Japanese Journal of Social Psychology, 27(3), 185-192.

Higuchi, O., Hanita, K., \& Fujishima, Y. (2010). The effects of achievement motivation and subjective temporal distance to deadline on planning fallacy. Japanese Journal of Experimental Social Psychology, 49(2), 160-167.

Hsee, C. K., \& Abelson, R. P. (1991). Velocity relation: Satisfaction as a function of the first derivative of outcome over time. Journal of Personality and Social Psychology, 60(3), 341-347.

Idson, L. C., Liberman, N., \& Higgins, E. T. (2004). Imagining how you'd feel: The role of motivational experiences from regulatory fit. Personality and Social Psychology Bulletin, 30(7), 926-937.

Joshi, P. D., \& Wakslak, C. J. (2014). Communicating with the crowd: Speakers use abstract messages when addressing larger audiences. Journal of Experimental Psychology: General, 143(1), 351-362.

Karsh, N., \& Eyal, T. (2015). How the consideration of positive emotions influences persuasion: The differential effect of pride versus joy. Journal of Behavioral Decision Making, 28(1), 27-35.

Kluger, A. N., \& DeNisi, A. (1996). The effects of feedback interventions on persistence: A historical review, a meta-analysis, and a preliminary feedback intervention theory. Psychological Bulletin, 119(2), 254-284.

Koo, M., \& Fishbach, A. (2008). Dynamics of self-regulation: How (un)accomplished goal actions affect motivation. Journal of Personality and Social Psychology, 94(2), 183-195. 
Kruglanski, A. W., Shah, J. Y., Pierro, A., \& Mannetti, L. (2002). When similarity breeds content: Need for closure and the allure of homogeneous and self-resembling groups. Journal of Personality and Social Psychology, 83(3), 648-662.

Lewin, K., Dembo, T., Festinger, L., \& Sears, P. (1944). Level of Aspiration. In J. M. Hunt (Ed.), Personality and the behavior disorders (pp. 333-378). Oxford: Ronald Press.

Locke, E. A., \& Lantham, G. P. (1985). The application of goal setting to sports. Journal of Sport Psychology, 7(3), 205-222.

Locke, E. A., \& Latham, G. P. (1990). A theory of goal setting and task persistence. Englewood Cliffs. NJ: Prentice Hall.

Locke, E. A., \& Latham, G. P. (2002). Building a practically useful theory of goal setting and task motivation: A 35-year odyssey. American Psychologist, 57(9), 705-717.

Louro, M. J., Pieters, R., \& Zeelenberg, M. (2007). Dynamics of multiple-goal pursuit. Journal of Personality and Social Psychology, 93(2), 174-193.

Miller, G. A., Galanter, E., \& Pribram, K. H. (1960). Plans and the Structure of Behavior. Rinehart and Winston, New York: Holt.

Nevo, B. (1985). Face validity revisited. Journal of Educational Measurement, 22(4), 287-293.

Pervin, L. A. (1989). Personality: Theory and Research (5th ed.). New York: Wiley.

Pintrich, P. R., \& Schunk, D. H. (2002). Motivation in education: Theory, research, and applications (2nd ed.). Upper Saddle River, NJ: Merrill, Prentice Hall.

Shah, J., Higgins, E. T., \& Friedman, R. (1998). Persistence incentives and means: How regulatory focus influences goal attainment. Journal of Personality and Social Psychology, 74(2), 285-293.
Sloman, S. A. (1996). The empirical case for two systems of reasoning. Psychological Bulletin, 119(1), 3-22.

Teunissen, P. W., \& Bok, H. G. J. (2013). Believing is seeing: How people's beliefs influence goals, emotions and behaviour. Medical Education, 47(11), 1064-1072.

Tolman, E. C. (1955). Principles of persistence. Psychological Review, 62(5), 315-326.

Vallacher, R. R., \& Wegner, D. M. (1989). Levels of personal agency: individual variation in action identification. Journal of Personality and Social Psychology, 57(4), 660-671.

Vallacher, R. R., Wegner, D. M., \& Somoza, M. P. (1989). That's easy for you to say! Action identification and speech fluency. Journal of Personality and Social Psychology, 56(2), 199-208.

Webb, T. L., \& Sheeran, P. (2006). Does changing behavioral intentions engender behavior change? A meta-analysis of the experimental evidence. Psychological Bulletin, 132(2), 249-268.

Wigfield, A., \& Eccles, J. S. (2000). Expectancy-value theory of achievement motivation. Contemporary Educational Psychology, 25(1), 68-81.

Yeager, D. S., Henderson, M., Paunesku, D., Walton, G., Spitzer, B., D'Mello, S., \& Duckworth, A. L. (2014). Boring but important: A self-transcendent purpose for learning fosters academic self-regulation. Journal of Personality and Social Psychology, 107(4), 559580 .

Publisher's Note Springer Nature remains neutral with regard to jurisdictional claims in published maps and institutional affiliations. 